\title{
Ingestive Behaviour Activities Based on Bioacoustic Signals in Grazing Cattle
}

\author{
Guilherme Augusto Defalque, College of Computing, Federal University of Mato Grosso do Sul, Brazil \\ (iD) https://orcid.org/0000-0002-7175-9992 \\ Ricardo Santos, College of Computing, Federal University of Mato Grosso do Sul, Brazil \\ iD https://orcid.org/0000-0002-2955-8011 \\ Victor Leonardo Yoshimura, College of Computing, Federal University of Mato Grosso do Sul, Brazil \\ (iD) https://orcid.org/0000-0002-4271-2140 \\ Fabiana Villa Alves, Brazilian Agricultural Research Corporation / Embrapa Beef Cattle, Embrapa, Brazil \\ iD https://orcid.org/0000-0002-4244-940X
}

\begin{abstract}
This work focuses on the development of an autonomous, electronic platform based on bioacoustic techniques to monitor animal sounds related to ingestive activities and sub-activities in beef cattle. The authors have developed an electronic platform that leverage the usage of applications to predict health and welfare conditions based on the bioacoustic signals. The platform architecture is comprised of electronic subsystems covering the signal acquiring and filtering; sampling, processing, data storage system; and the coupling of the electronic and computing. The platform is coupled to the animal's halter so that the electronic system is in a case on the animal's forehead. Experiments were performed on grazing cattle (Nelore breed) in three field tests. The system was fully able to acquire, process, and store the animal's bioacoustic sounds. The authors used an audio file processing software to identify ingestive activities such as grazing, rumination, and idle periods. The results, based on the signal waveform, achieved high accuracy when compared to the visual monitoring method.
\end{abstract}

\section{KEYWORDS}

Beef Cattle, Bioacoustic Signals, Electronic Device, Grazing Cattle, Ingestive Behaviour, Nelore Breed, NonInvasive, Welfare

\section{INTRODUCTION}

Market demands have raised the level of requirements concerning quality of food products, and specifically, the quality of animal products (milk and meat). Such demands encourage research on factors that influence behaviour parameters that are directly or indirectly related to animal husbandry, such as animal welfare.

The behaviour of an animal can be a clear indicator of its physiological state (Frost et al., 1997). Under thermal stress, cattle change their behaviour as a way to regulate body temperature and to maintain homothermia (Volpi et. al., 2020). These mechanisms can be physiological and/ or behavioural, including changes in ingestive behaviour as a way to overcome adverse situations, whether related to environment temperature or to the quality and quantity of food available. The

This article, originally published under IGI Global's copyright on October 1, 2020 will proceed with publication as an Open Access article starting on February 2, 2021 in the gold Open Access journal, International Journal of Agricultural and Environmental Information Systems 
ingestive activities (grazing and rumination) can be indicators the animal health, welfare or nutrition status (De Boever et al., 1990), once that an animal changes its eating habits when it has its routine modified due to physical changes in the body or the environment. Monitoring ingestive behaviour is a procedure that helps early detection of diseases, improving welfare and reducing economic losses.

One commonly adopted procedure to monitor ingestive behaviour in cattle is the visual method (Figure 1, item 2). This method allows experts to identify, while cattle grazing, activities and jaw movements related to ingestive behaviour. This process requires the observers to be at a significant distance from the animals in order not to disrupt their natural routine. Experts are responsible for taking notes on ingestive behaviour and animal's environment and positioning data (weather, temperature, animal position, etc). Despite being a well-known and simple procedure, the visual approach lacks scale and accuracy, since it is a time-consuming, and error-prone method, requiring an expert to be on site, monitoring the animal, and taking notes of its activities (Volpi et. al., 2020).

This work presents a non-invasive device to monitor ingestive behaviour based on the bioacoustic technique (Figure 1, item 1). The bioacoustics technique is a tool to characterize animal behaviour from the sounds they produce. The no-vocal sounds produced by the jaw when performing activities related to ingestive behaviour are the focus of many studies (Volpi et. al., 2020), (Chelotti et. Al., 2016). Those studies have used the bioacoustics technique, visual method, and labelling method for validation purposes.

The Labeling method (Figure 1, item 3) is commonly used in bioacoustics data to characterize events and compare results as well as it works as an important tool in the dataset training for machine learning algorithms (Tullo et. al., 2017), (Chelotti, et. al., 2016). It consists in the observation, extraction, identification, and classification of individual animal sounds based on amplitude or frequency of the sound signal (Tullo, et. Al., 2017). Figure 1 presents BPMN (Business Process Management Notation) diagrams correlating the bioacoustics technique to the visual method and labeling method. The bioacoustic technique uses the visual method and labelling method to perform the validation process and to serve as a basis for sound data capture.

We have designed and developed a low-cost, non-invasive computational and electronic device for the acquisition, processing, storage, and transmission of bioacoustics signals in grazing cattle. We have evaluated the device in grazing Nelore (Bos indicus) cattle and compared the results to the visual technique to identify ingestive behaviour activities. In addition to the flexibility and automatic data acquisition brought by the device, our tests showed that the proposed solution achieved high accuracy compared to the visual technique on detecting activities such as ruminating, idle, and grazing.

\section{RELATED WORK}

In order to meet scale accuracy demands, automated solutions are being developed to replace the visual method. Some automated solutions to detect animal's ingestive behaviour has been based on accelerometery, electromyography, pressure sensors, and bioacoustic (Andriamandroso et. al., 2016). Among those techniques, bioacoustic has shown to be a promising support tool by acquiring data on feeding parameters (biting and chewing events) to perform detailed data analysis and to predict cattle welfare based on grazing, rumination, and idle activities.

Most of the research work on bioacoustic signals focused on the development of algorithms to predict behaviour or proposing hardware based on commercial components (records and microphones) (Volpi et. al., 2020), (Clapham, et. al., 2011), (Milone et. Al., 2012), (Chelotti, et. al., 2016), (Deniz et. al., 2017), (Laca \& WallisDeVries, 2000). Proposals focusing on off-the-shelf components along with the visual method were used to identify ingestive activities achieving an accuracy of up $95 \%$ (Clapham et. al., 2011), (Laca \& WallisDeVries, 2000).

Artificial intelligence techniques have been used in jaw movements recognition softwares for ingestive behaviour, such as Hidden Markov Models (Milone et. al., 2012) and Machine Learning (Navon et. al., 2013) achieving accuracies of 94\%. Others authors ((Navon et. al., 2013) and (Chelotti 
Figure 1. BPMN diagram of bioacoustic technique applied in grazing cattle

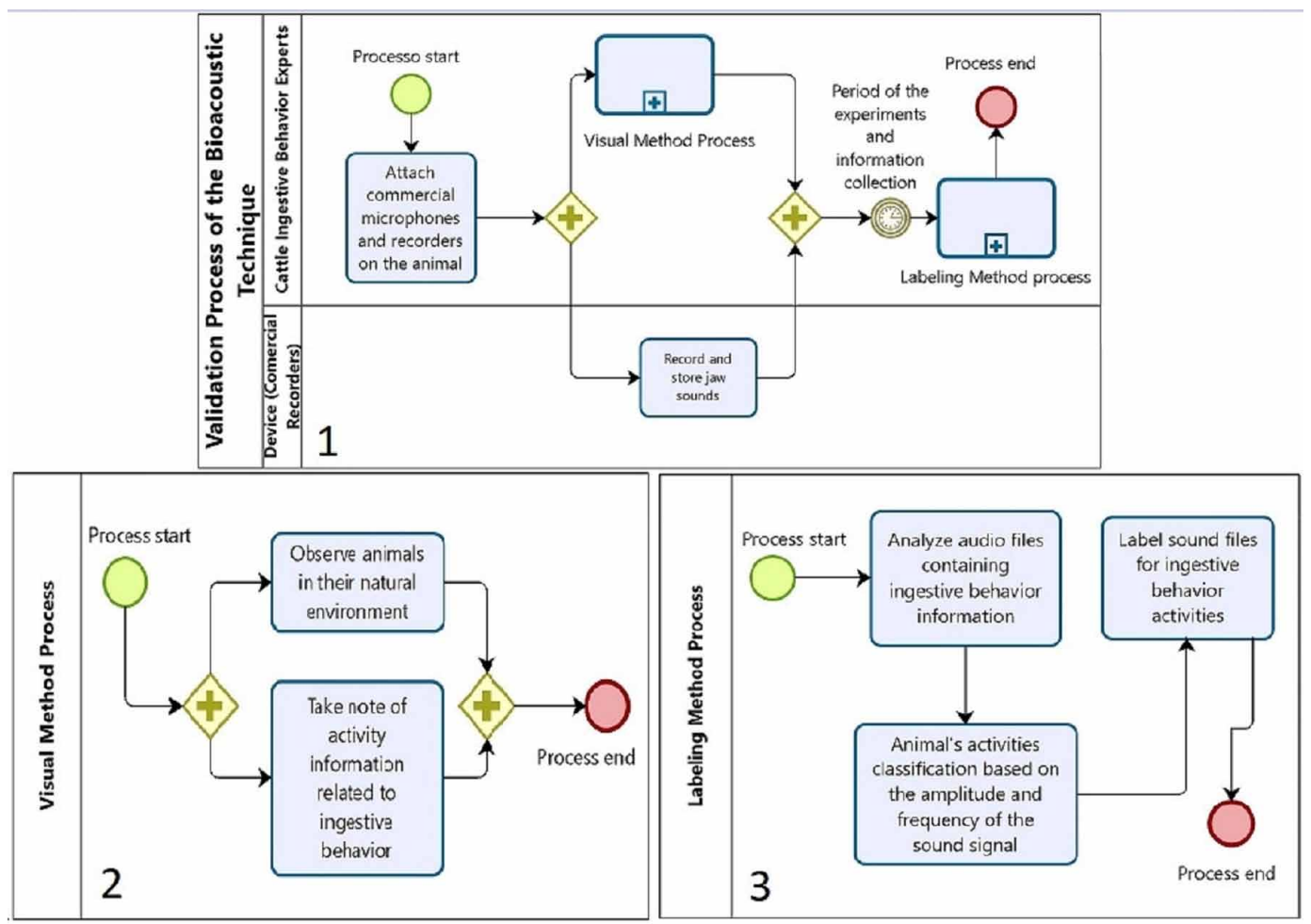

et. al., 2016)) adopted time domain techniques to identify events that characterized jaw movements of the ingestive behaviour and developed an algorithm capable of identifying and classifying jaw movements of ingestive behaviour with accuracy of $97.4 \%$. Few studies focused on the development of devices for ingestive behaviour monitoring. One the most recent studies (Deniz et. al., 2017) aimed to develop a platform with a large set of functionalities for real-time monitoring of ingestive behaviour. The tests were performed in the laboratory, where a database of labeled sounds of jaw movements of the ingestive behaviour was reproduced providing accuracies on identification of $92 \%$ and classification of $78 \%$.

Despite many methods, algorithms, and prototypes, there is still a gap in proposals focusing on devices and technologies that show feasibility at field usage. The focus of the previous work have been on monitoring ingestive parameters on dairy cattle. For grazing beef cattle, such as Nelore breeds, viable technological solutions should be durable, autonomous, and non-invasive to meet the animal's behaviour.

\section{ELECTRONIC DEVICE}

We have designed an electronic device for bioacoustics signal acquisition that is used on the animal's forehead. The electronic device location is based on previous work (Milone et. al., 2012), (Deniz et. al., 2017) and (Volpi et. al., 2020) indicating that ingestive sounds can propagate along the skull thus being able to be acquired in a point of less attenuation. The electronic device is comprised of subsystems which are prototyped in Printed Circuit Boards and stored in a case, which is on the animal's forehead, as presented in Figure 2. 
Figure 2. Electronic circuits are embedded into a case on the animal's front head band

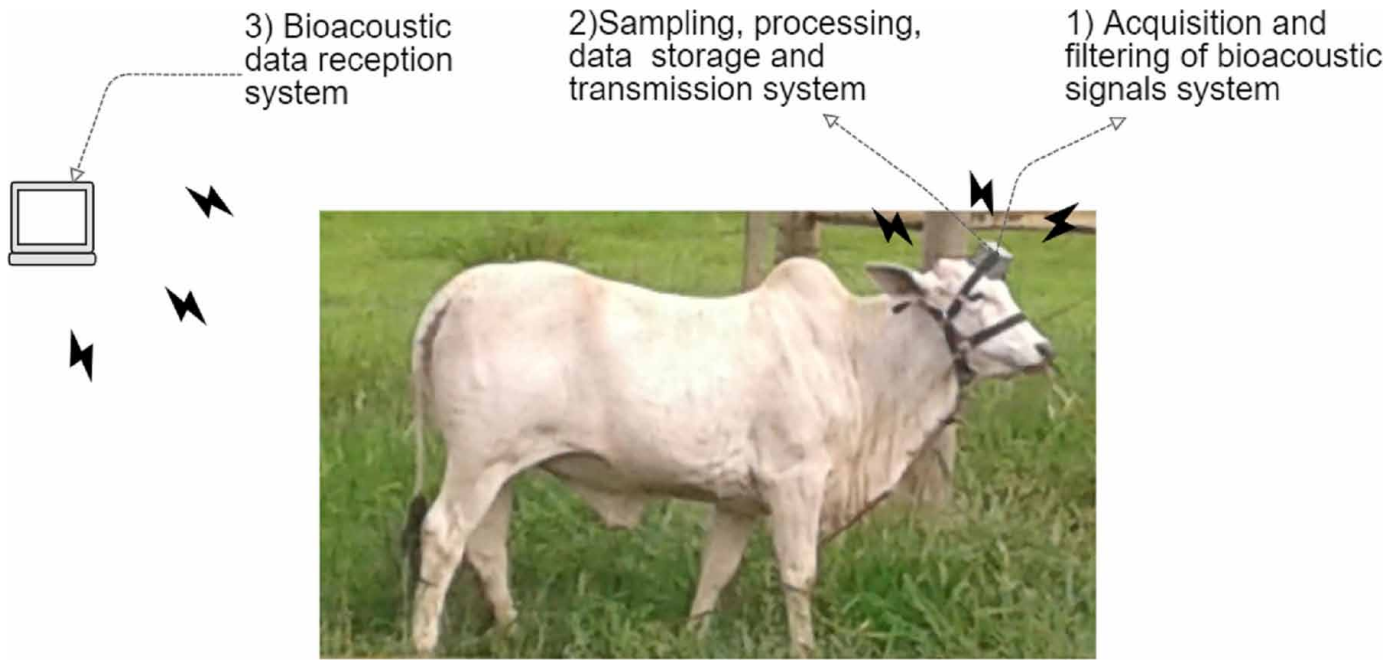

The subsystems are organized to Figure 3: acquiring and filtering system (subsystem 1); processing, storage and transmission system (subsystem 2); and reception of bioacoustics signals system (subsystem 3).

\section{Acquisition and Filtering of Bioacoustics Signals Subsystem}

This subsystem acquires signals of mandibular sounds (Figure 4 (A), item 5) using a microphone capsule (A, 1), wrapped in an insulation material (smooth acoustic foam). The low amplitude signals of the electret capsule are amplified by a circuit in an inverting topology (A, 2) and a bias DC circuit

Figure 3. Block diagram of the bioacoustic device

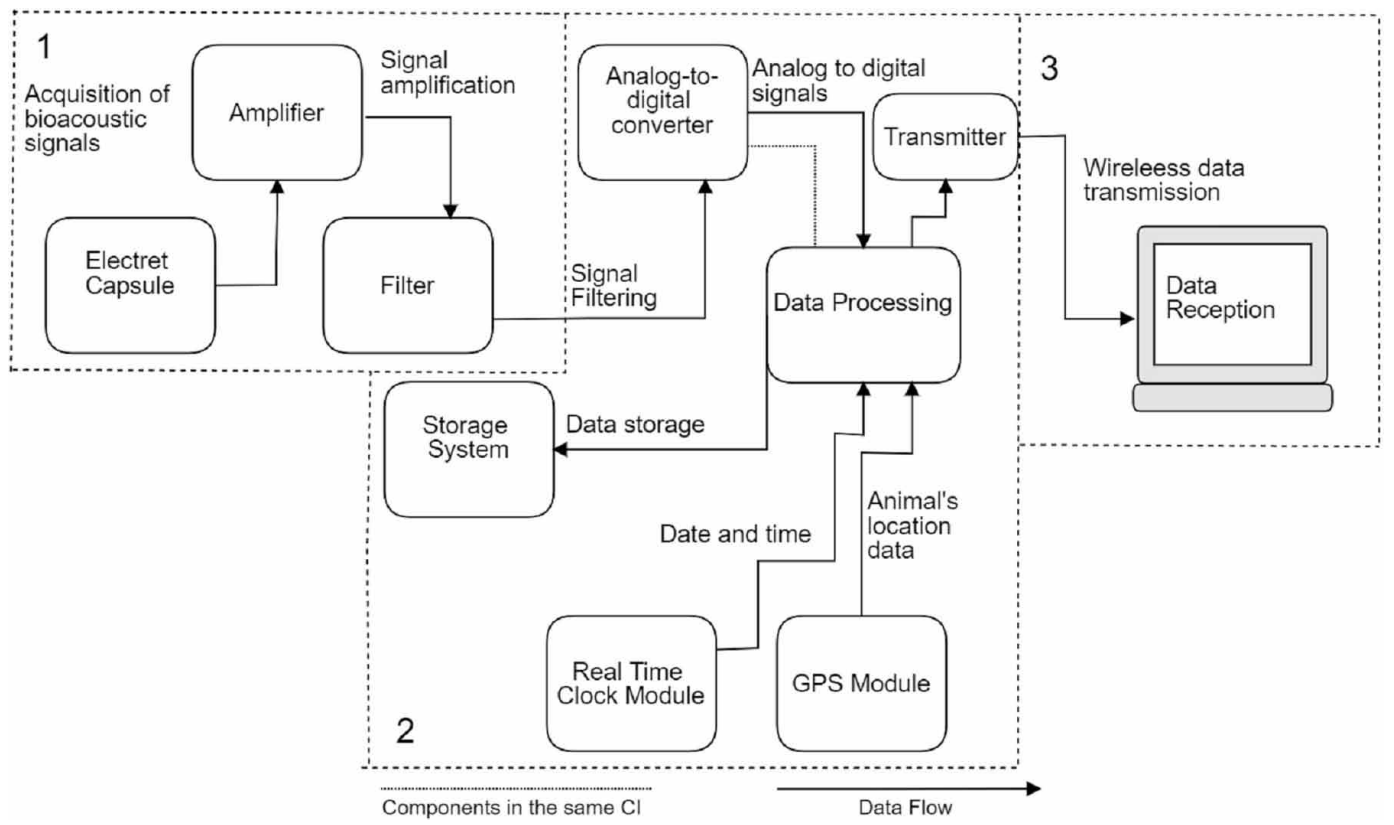


(A, 3) performs an offset signal of $2 \mathrm{~V}$, which enables the signals to be read by an analog-to-digital converter. The amplification factor is performed by a digital potentiometer (A, 4) designed with a CD4066 IC (Figure 4 (B)). The acoustic foam prevents the influence of noises caused by wind, other external noises, and sounds caused by the animal itself. An analog filter is used to minimize unwanted signals (noise). The filter (A, 8) is a fourth-order Butterworth type, composed of two second-order filters in cascade by Sallen-Key topology (items 6-7 in Figure 4(A)). The filter cut-off frequency is $2.6 \mathrm{kHz}$.

The four resistors (R11, R5, R14, and R15) in Figure 4 (B), are enabled by the selection switches of the CD4066 IC (JP2 and JP3 in Figure 4 (B)) by digital ports contained in the main board (item 7 in Figure 5), providing a minimum resistance of $1 \mathrm{kOhm}$ (approximate internal resistance of the

Figure 4. Acquisition and filtering subsystem electronic schematic (A) and digital potentiometer design (B)

1 - Electret capsule and
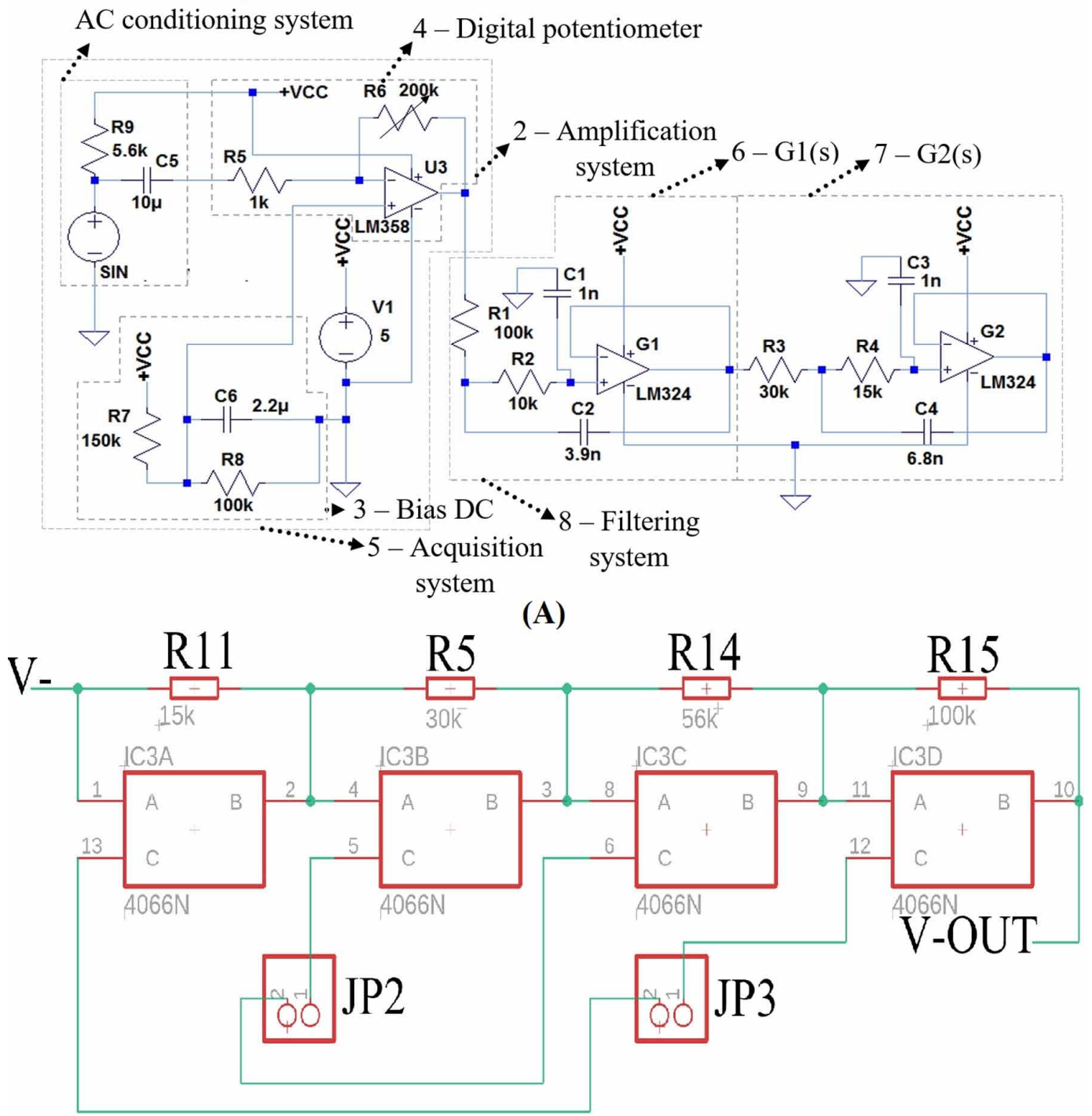

(B) 
CD4066 IC) up to 200kOhms (when all the selection switches are disabled). The potentiometer is connected as shown in resistor 6 (Figure 4 (A), item 4), at the inverter input and at the output of the operational amplifier, being one of the tools to realize the gain factor of the microphone.

\section{Processing and Transmission Subsystem}

This subsystem (Figure 5) has an input for GPS Vk2828u7g5lf module (5) capable of collecting animal's location (latitude and longitude), a read and write module for micro SD cards (1) that stores GPS data and bioacoustics sounds data, a Real Time Clock DS1307 IC (3), an ATMega1284p microcontroller (4) for data processing, a microphone input for the microphone system (6) and an HC06 Bluetooth transmitter module (2). All the modules and ICs are represented by the electronic schematic in Figure 5.

The device power supply circuit (Figure 6) consists of a 1800mAh, 3.7V Li-Ion battery output (4), a battery charger module TP-4056 (1) with micro USB interface for battery charging, a boost module MT3608 (2) that converts the battery voltage from an input of $3.7 \mathrm{~V}$ to an output of $7.2 \mathrm{~V}$, enough to power up a voltage regulator module LM7805 (3), which (together with two capacitors) maintain the supply voltage of the entire system at $5 \mathrm{~V}$.

\section{Bioacoustics Information and Data Reception Subsystem}

This subsystem receives data from the processing and transmission subsystem (Figure 5) encoded in PCM (Pulse Code Modulation). It is responsible for receiving and storing the sound and GPS data files in an independent computer system. The software reception system was developed in Python 3.6 language. Figure 7 shows a flowchart of the communication protocol that has been developed and tested in laboratory.

\section{DEVICE PROTOTYPE}

All subsystems were built on specific Printed Circuit Boards (PCBs) designed using Autodesk Eagle $^{\mathrm{TM}}$ software. The PCBs are stored into a case based on PolyLactic Acid (PLA) material. Figure 8 (A) presents all the technological apparatus designed inside the case and protected with smooth acoustic foam.

The case is placed on the animal's forehead using a custom-made halter (Figure 8 (B)) to fix the case onto the animal's forehead and neck. The halter has a tape that allows the case to be fixed to the cattle forehead (Figure 8 (B), item 1), a tape that surrounds the lower part of the animal's neck

Figure 5. Electronic components for sampling, processing, and communication

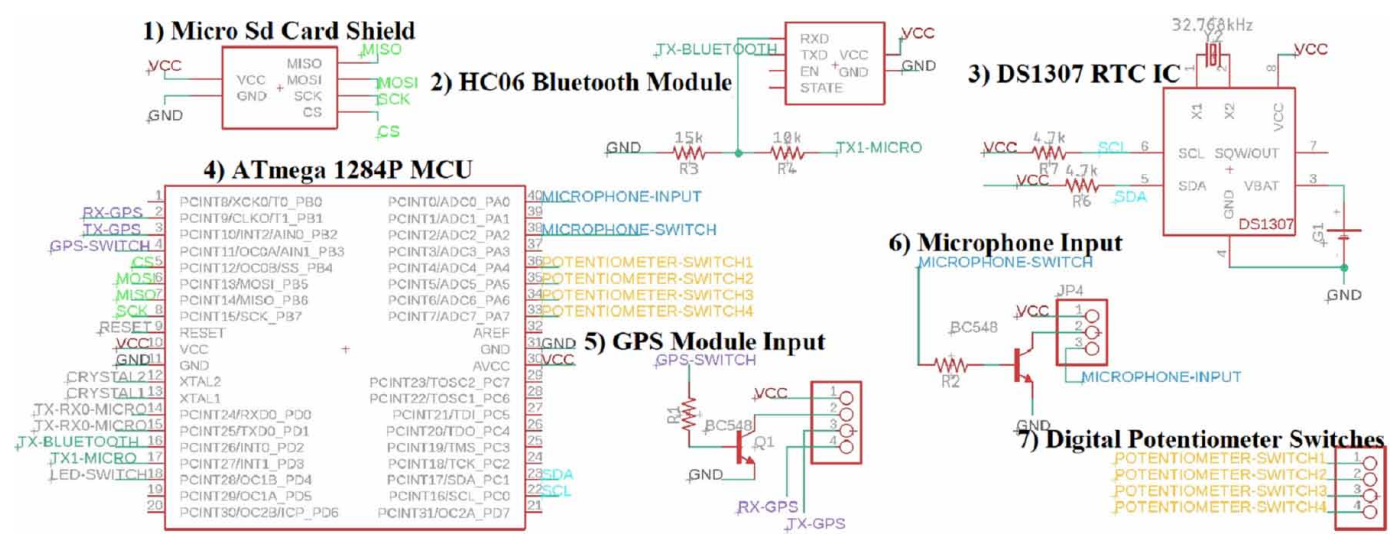


Figure 6. Power supply system electronic schematic

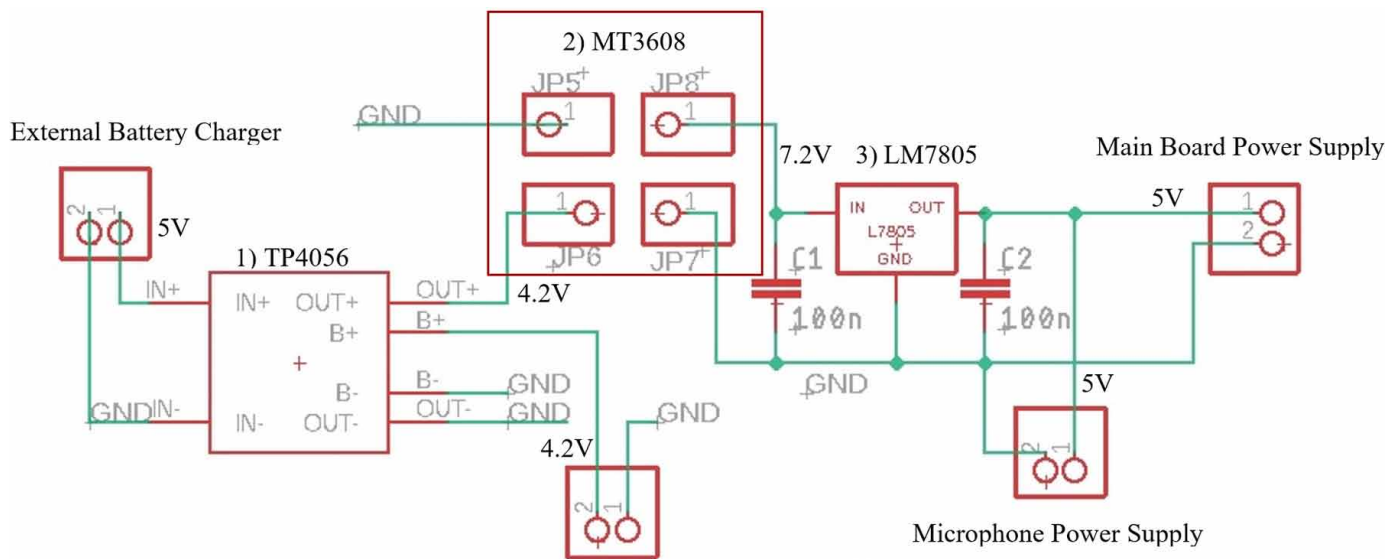

4) Battery Output

Figure 7. Flowchart of communication between the receiver software and the platform

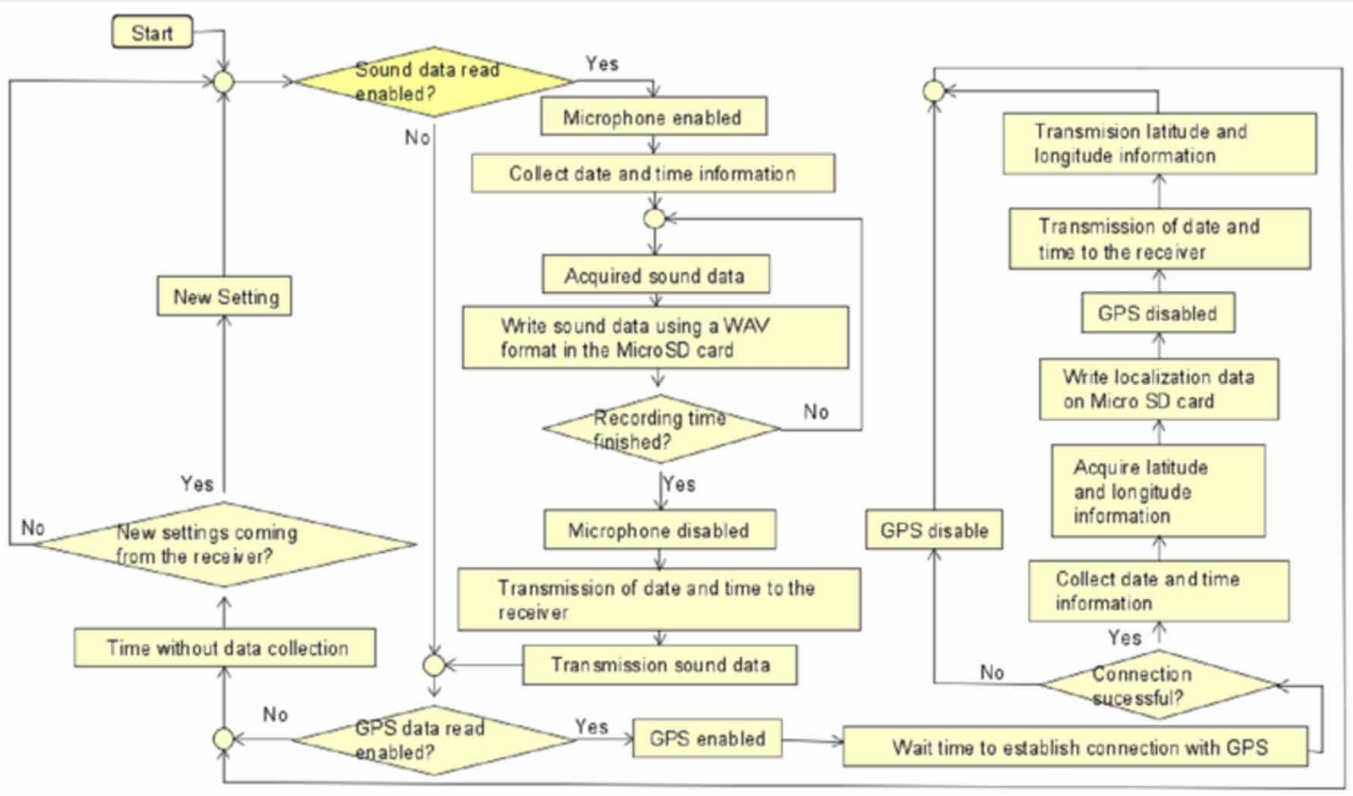

(2) and a tape for attachment to the contour of the neck (4). In addition, a leather band (3) passes over the animal's head. The case has 3.82 inches length, 3.43 inches width, 3.54 inches height and a weight of 350 grams.

Table 1 shows the maximum continuous consumption $(\mathrm{mA})$ for all subsystems. In Data transmission and Localization Subsystems (GPS and Bluetooth) the direct current of the location acquisition system (GPS) is $32 \mathrm{~mA}$ when data is being acquired and the maximum consumption of the transmission system is $30-40 \mathrm{~mA}$, however, without data transmission, its consumption is around $8 \mathrm{~mA}$; in the storage and processing subsystem, the microSD Card Module consumes 200mA when in write mode. Acquisition and Filtering Subsystem consumes maximum continuous of $3.6 \mathrm{~mA}$, 
Figure 8. Electronic device case and and halter
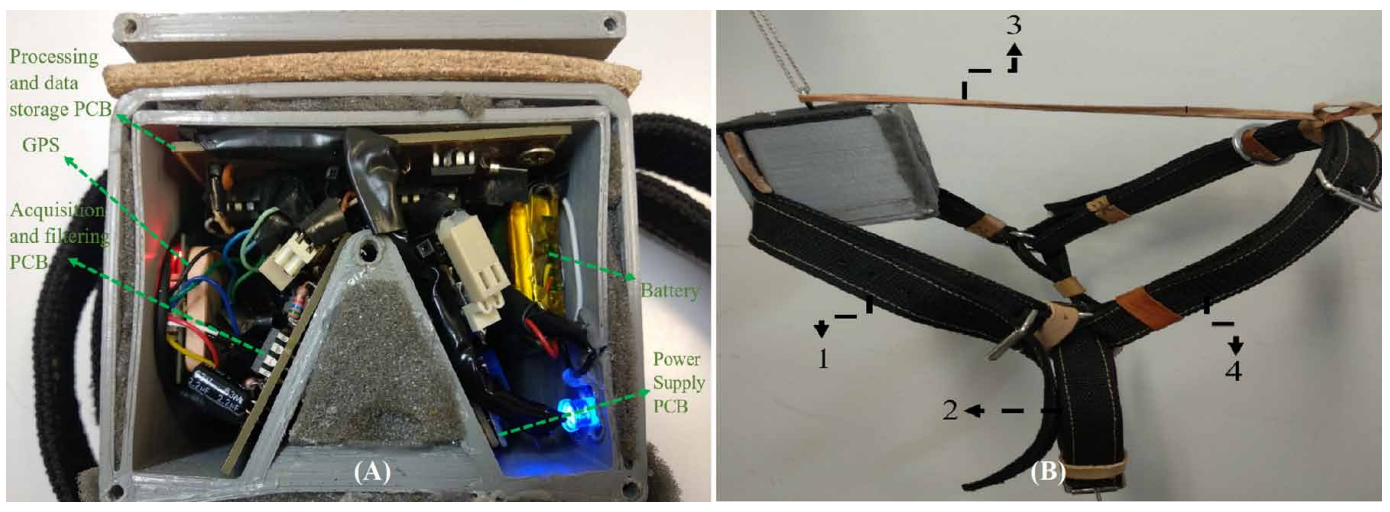

where, Two LM324 are responsible for consuming most of the continuous current (2.4 mA). Power Supply Subsystem consumes $8.3 \mathrm{~mA}$ and LM7805 is the component that consumes practically all the current of the subsystem (8mA).

\section{EXPERIMENTS AND RESULTS}

Experiments were carried out at the High Performance Computing Systems Laboratory (LSCAD) of the Federal University of Mato Grosso do Sul (UFMS) and at EMBRAPA Beef Cattle to observe and analyse the platform performance and suitability to be used by Nelore animals. The laboratory experiments took 20 hours and generated about $300 \mathrm{MB}$ of sound data. Experiments and test at field took approximately 9 hours generated about $254 \mathrm{MB}$ of new sound data.

In order to test and validate the device, we performed experiments in the laboratory using a labelled dataset from grazing, rumination, and idle activities (Volpi et. al., 2020). The dataset consists of bioacoustics ingestive data from 12 Nelore cows grazing at a pasture of Brachiaria brizantha. Each animal was 30 months old and had an average live weight of 400kg. Each animal used a generic lapel

Table 1. Main components and maximum current consumption

\begin{tabular}{|c|c|c|}
\hline Component & Components & $\begin{array}{c}\text { Maximum continuous total } \\
\text { consumption (mA) }\end{array}$ \\
\hline $\begin{array}{c}\text { Acquisition and Filtering } \\
\text { Subsystem }\end{array}$ & LM358 \\
Two LM324 & 3.6 \\
CD4066 & 8.3 \\
\hline Power Supply Subsystem & TP-4056 & \\
\hline Mata Transmission and & LM7805 & 75 \\
Localization Acquisition & HC06 & \\
Subsystems & GPS - & \\
\hline & VK2828U7G5LF & 225.5 \\
Processing and data store & Micro SD Card Module & \\
subsystem & ATMega1284p & \\
& RTC - DS1307 & \\
\hline
\end{tabular}


microphone and digital voice recorder (Sony, 100 ICD-PX240 ${ }^{\mathrm{TM}}$ ). After recording the sound data, experts labeled the collected data comparing the bioacoustics signals to the visual method annotations.

We performed an experiment to evaluate if our device could acquire sound data from the dataset and to compare the signals waveforms. The experiment was reproduced in an acoustically isolated room, the audio files representing the activities of the ingestive behaviour were visually compared to the excerpts from the dataset using the Ocenaudio ${ }^{\mathrm{TM}}$ software. Even though the data from the dataset were acquired with different parameters for acquisition and sampling (44kHz sampling was used in the dataset recorder) compared to our device, the results showed visual and auditory similarity.

Another set of experiments were performed at the field, in a grazing paddock with water, forage and dry minerals available. These experiments used the platform shown in Figure 8 . The data acquisition workflow was performed according to Figure 7. The data acquisition time interval was setup before the start of each experiment. The transmission system was not enabled at field tests so that all sound data were stored and available into the micro SD card.

Figure 9 shows images of the field tests carried out at the in the Agricultural Research Corporation (EMBRAPA Beef Cattle). Animals were 20 months old (Nelore heifers). Table 2 presents the date, time, battery consumption level, sound data record setup and the main results of each test.

As presented in Table 2, the first test was performed on October 26th, 2018. It allowed for finetuning in the halter, circuits, and case. The second test (November 26th, 2018) showed normal circuit operation in sound capture and data storage. The test on December 21st, 2018, targeted platform validation so that an expert, using the visual method, was taking notes on ingestive behaviour

Figure 9. Animal using the bioacoustics device while grazing
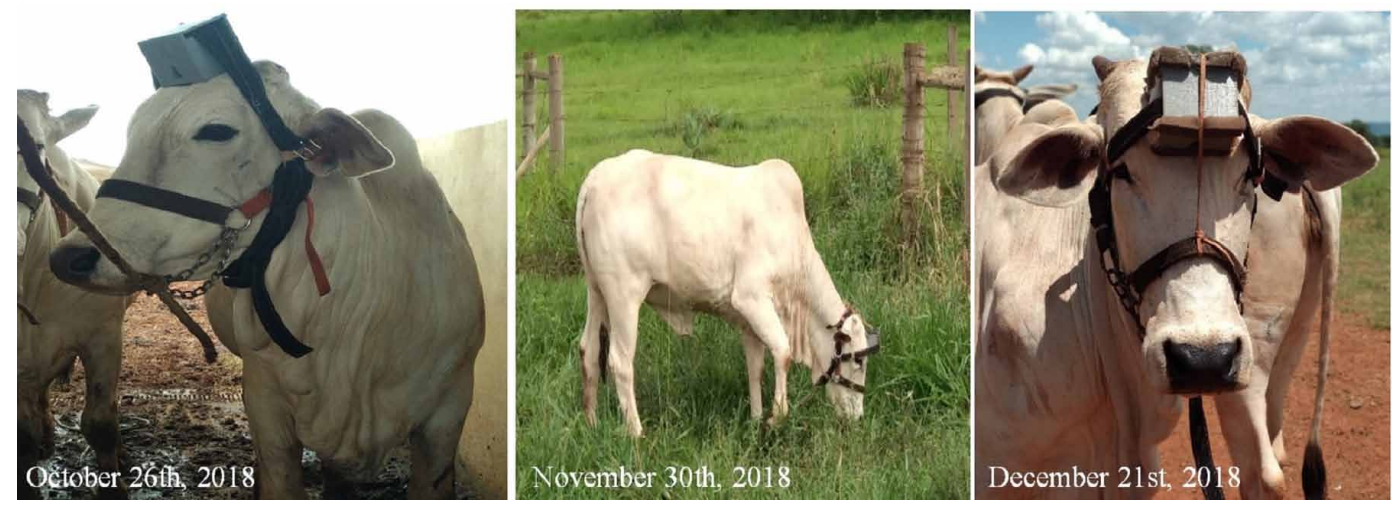

Table 2. Summary of the field tests

\begin{tabular}{|c|c|c|c|c|}
\hline Date & Hour & Battery (V) & Sound data setup & Results \\
\hline $\begin{array}{l}\text { October 26th, } \\
2018\end{array}$ & 08:55 - 09:17 a.m. & $4.12-4.06$ & \multirow{2}{*}{$\begin{array}{l}1 \text { minute per file, } \\
3 \text { minutes interval } \\
\text { between recordings }\end{array}$} & $\begin{array}{l}\text { Halter and circuit case } \\
\text { validation }\end{array}$ \\
\hline $\begin{array}{l}\text { November 30th, } \\
2018\end{array}$ & 08:38 -10:35 a.m. & $4.11-4.02$ & & $\begin{array}{c}\text { Normal circuit operation } \\
\text { for sound acquisition and } \\
\text { data storage }\end{array}$ \\
\hline $\begin{array}{c}\text { December } 21 \text { st, } \\
2018\end{array}$ & 08:15 - 02:07 p.m. & $4.20-3.89$ & $\begin{array}{l}2 \text { minutes per file, } \\
3 \text { minutes interval, } \\
\text { between recordings }\end{array}$ & $\begin{array}{c}\text { Acquisition and storage } \\
\text { data and comparison of } \\
\text { bioacoustics data with } \\
\text { analysis made through } \\
\text { visual observation } \\
\text { method }\end{array}$ \\
\hline
\end{tabular}


(rumination, grazing, and idle) from one animal every 10 minutes. Some extra samples to the sampling period were collected, as we aimed to collect as many samples as possible from the three activities of ingestive behaviour. We performed a visual and auditory analysis of the recorded sounds and compared the activities of the ingestive behaviour to the visual method using the Ocenaudio ${ }^{\mathrm{TM}}$ software.

Figures 10 and 11 show, respectively, sound patterns of grazing and rumination activities. Figure 12 presents signal found when the animal performs some other type of activity (idle). In Figures 10-12 the vertical axis represents the analogue signal waveform and the Hertz values of frequencies. The horizontal axis represents the elapsed time in miliseconds.

The analyses of sound samples in Figure 10 showed that grazing events ranged from 0.4 to 1 seconds (in continuous stream of activity), where each event had higher signal intensities than rumination. Variations on signal intensity occur due to the bite events (which are responsible for signals with greater amplitudes), chew events (signals without steep, moderate peaks) and chew-bite events, a combination of both movements. Grazing signals showed higher energy peaks at frequencies up to $4 \mathrm{kHz}$ which corroborate to some previous scientific studies (Volpi et. al., 2020), (adriamandroso et. al., 2016).

Rumination activity was characterized with a low amplitude of signals. The signals with low amplitude can be explained considering that a chewing of regurgitated forage occurs, requiring a lower chewing intensity compared to the grazing activity. Rumination events were identified at intervals from 0.5 up to 0.8 seconds. Each event had 0.15 to 0.35 seconds. The frequencies with higher intensities were characterized close to $2 \mathrm{kHz}$.

Table 3 presents a summary of comparing the manual labeling with the bioacoustic signal identification from our device. The results are from the samples acquired in the experiment on December 21st, 2018.

The periods where the device results indicate "Device was idle" were attempts to acquire location data using GPS or by programmed idle periods for power saving. Considering the periods that the platform performed signals acquisition (disregarding the periods where the platform was idle), compared to the visual method, the data acquired from the device presented high accuracy for each

Figure 10. Acoustic signals from the grazing activity

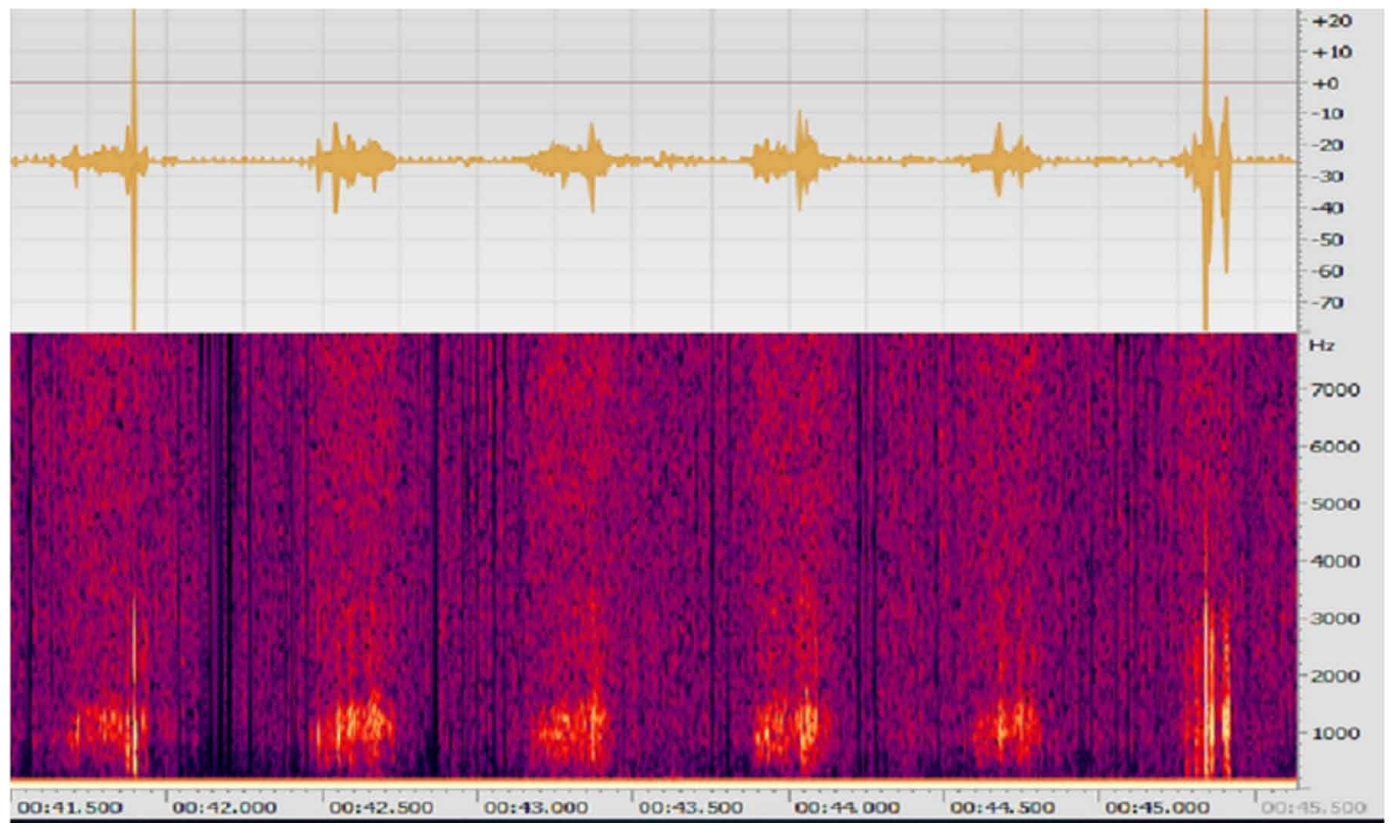


Figure 11. Acoustic signals from the rumination activity

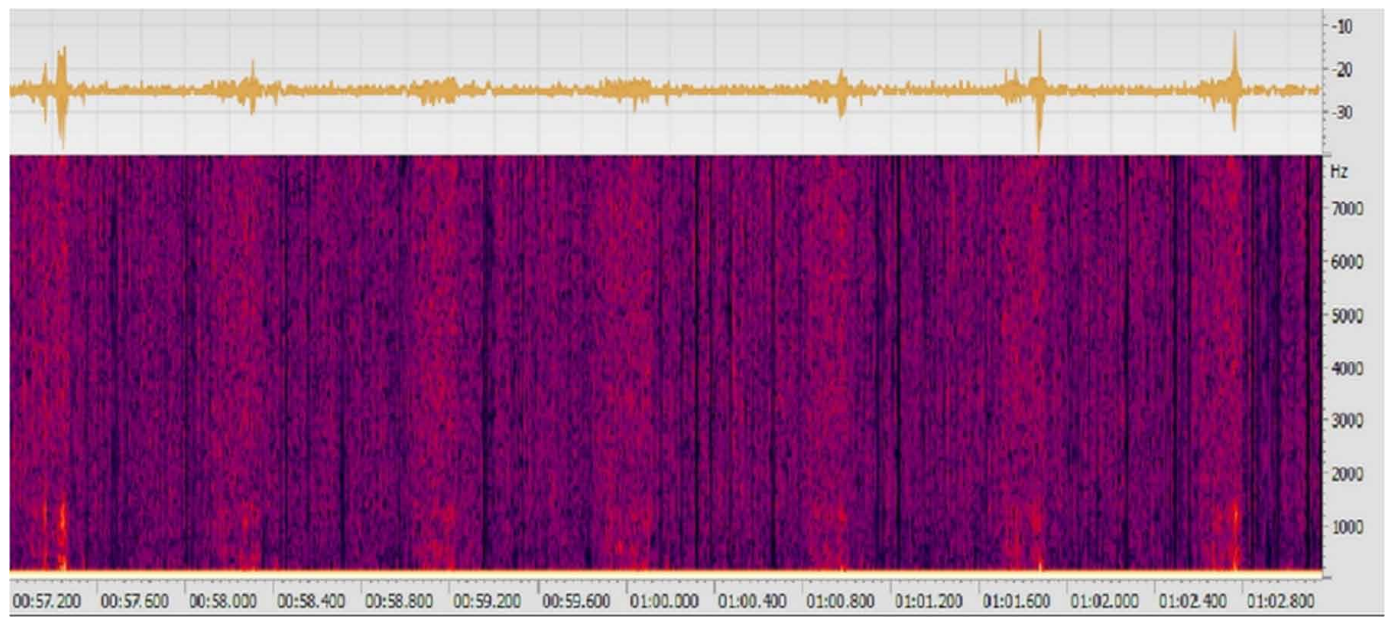

Figure 12. Acoustic signals from the idle activity

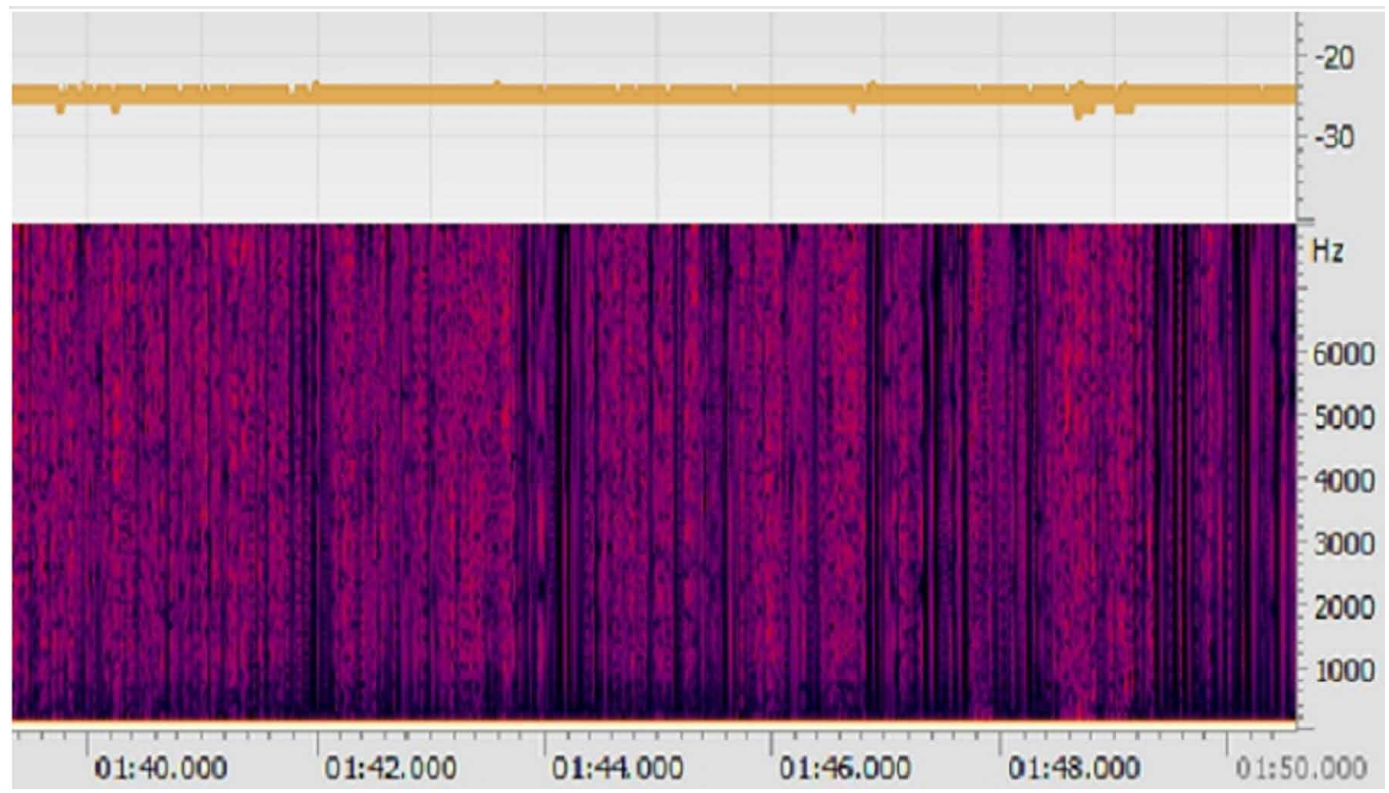

activity of the ingestive behaviour (grazing, rumination, and idle). We calculate the standard deviation, sample mean, and variance of the sample data from the rumination, idle, and grazing datasets. The variance of the grazing dataset was 2.47 , rumination was 0.43 , and idle 0.27 . The standard deviation for all datasets were 1.57 (grazing), 0.66 (rumination), and 0.27 (idle). The sample mean was 102.8 (grazing), and 102.9 (idle). Since there are a larger number of samples in each dataset (larger than 1000000 samples), the mean difference was not significant among the acitivies. 
Table 3. Comparison between the visual method and the bioacoustic device results

\begin{tabular}{|c|c|c|c|}
\hline Hour & Note & Visual Method & Bioacoustic Method \\
\hline 11:00 a.m. & AWSS & Idle & Idle \\
\hline 11:10 a.m. & AWSS & Idle & Idle \\
\hline 11:11 a.m. & AWSS & Idle & Idle \\
\hline 11:12 a.m. & AWSS & Idle & Device was idle \\
\hline 11:20 a.m. & AWSS & Idle & Idle \\
\hline 11:26 a.m. & AWSBC & Grazing & Grazing \\
\hline 11:30 a.m. & AWSS & Idle & Idle \\
\hline 11:40 a.m. & AWSS & Grazing & Grazing \\
\hline 11:50 a.m. & AWSS & Grazing & Grazing \\
\hline 12:00 p.m. & AWSS & Idle & Idle \\
\hline 12:03 p.m. & AWSS & Idle & Idle \\
\hline 12:10 p.m. & AWSS & Idle & Idle \\
\hline 12:20 p.m. & ALDSW & Rumination & Rumination \\
\hline 12:30 p.m. & ALDSW & Rumination & Rumination \\
\hline 12:36 p.m. & ALDSW & Rumination & Rumination \\
\hline $12: 40$ p.m. & ALDSW & Rumination & Rumination \\
\hline $12: 50$ p.m. & ALDSW & Idle & Device was idle \\
\hline 01:00 p.m. & ALDSW & Idle & Device was idle \\
\hline 01:10 p.m. & ALDSW & Idle & Idle \\
\hline 01:20 p.m. & AWSS & Idle & Idle \\
\hline 01:24 p.m. & AWSS & Grazing & Grazing \\
\hline 01:30 p.m. & AWSS & Grazing & Grazing \\
\hline 01:41 p.m. & AWSS & Grazing & Grazing \\
\hline
\end{tabular}

AWSS = Animal was standing, sunny weather; AWSBC = Animal was standing, sunny weather and clouds; ALDSW = Animal lying down, sunny weather.

\section{CONCLUSION AND FUTURE WORK}

This work presents a non-invasive device to acquire bioacoustics signals from grazing cattle. The device can be used as a support tool on experiments to identify ingestive behaviour activities such as idle, rumination, and grazing from bioacoustics signals.

The experiments in laboratory aimed at identifying bioacoustics waveform patterns from each ingestive activity and improving the design of the data transmission system. The experiments on grazing cattle at filed indicated that the device seems suitable for cattle usage, even for long-term experiments. We have used the device longer than 6 uninterrupted hours at field under environmental conditions such as sunny and rainy weather. Laboratory tests were also performed was in continuous operation presenting an autonomy of approximately 15 hours. The platform replacement to low energy consumption module is one of the activities we intend to take in account to improve the platform energy efficienty.

To the best of our knowledge, the proposed electronic platform is a first solution on automatic bioacoustics signals acquisition able to be used as a long-term tool applied to grazing cattle. The electronic device can be used by applications focusing on automatically identify ingestive activities 
and sub activities from bioacoustics signals. It can be also used as a support tool to aid decisionmakers on providing more accurate information on ingestive behaviour, allowing for precise animal monitoring, that can optimize diets and other management practices that lead to improved animal welfare and performance.

\section{ACKNOWLEDGMENT}

The authors thank Brazilian Research Agencies FUNDECT, CAPES, and CNPq, for their financial support to this work. They also thank their institutions Federal University of Mato Grosso do Sul (UFMS) and EMBRAPA Beef Cattle for their infrastructure and logistics support to this work. 


\section{REFERENCES}

Andriamandroso, A., Bindelle, J., Mercatoris, B., \& Lebeau, F. (2016). A Review on the Use of Sensors to Monitor Cattle Jaw Movements and Behavior when Grazing. Biotechnologie, Agronomie, Société et Environnement, 20.

Chelotti, J. O., Vanrell, S. R., Milone, D. H., Utsumi, S. A., Galli, J. R., Rufiner, H. L., \& Giovanini, L. L. (2016). A Real-time Algorithm for Acoustic Monitoring of Ingestive Behavior of Grazing Cattle. Computers and Electronics in Agriculture, 127, 64-75. doi:10.1016/j.compag.2016.05.015

Clapham, W. M., Fedders, J. M., Beeman, K., \& Neel, J. P. (2011). Acoustic Monitoring System to Quantify Ingestive Behavior of Free-grazing Cattle. Computers and Electronics in Agriculture, 76(1), 96-104. doi:10.1016/j. compag.2011.01.009

De Boever, J. L., Andries, J. I., De Brabander, D. L., Cottyn, B. G., \& Buysse, F. X. (1990). Chewing Activity of Ruminants as a Measure of Physical Structure-A Review of Factors Affecting it. Animal Feed Science and Technology, 27(4), 281-291. doi:10.1016/0377-8401(90)90143-V

Deniz, N. N., Chelotti, J. O., Galli, J. R., Planisich, A. M., Larripa, M. J., Rufiner, H. L., \& Giovanini, L. L. (2017). Embedded System for Real-time Monitoring of Foraging Behavior of Grazing Cattle using Acoustic Signals. Computers and Electronics in Agriculture, 138, 167-174. doi:10.1016/j.compag.2017.04.024

Frost, A. R., Schofield, C. P., Beaulah, S. A., Mottram, T. T., Lines, J. A., \& Wathes, C. M. (1997). A Review of Livestock Monitoring and the Need for Integrated Systems. Computers and Electronics in Agriculture, 17(2), 139-159. doi:10.1016/S0168-1699(96)01301-4

Laca, E. A., \& WallisDeVries, . (2000). Acoustic Measurement of Intake and Grazing Behaviour of Cattle. Grass and Forage Science, 55(2), 97-104. doi:10.1046/j.1365-2494.2000.00203.x

Milone, D. H., Galli, J. R., Cangiano, C. A., Rufiner, H. L., \& Laca, E. A. (2012). Automatic Recognition of Ingestive Sounds of Cattle based on Hidden Markov models. Computers and Electronics in Agriculture, 87, 51-55. doi:10.1016/j.compag.2012.05.004

Navon, S., Mizrach, A., Hetzroni, A., \& Ungar, E. D. (2013). Automatic Recognition of Jaw Movements in Free-ranging Cattle, Goats and Sheep, using Acoustic Monitoring. Biosystems Engineering, 114(4), 474-483. doi:10.1016/j.biosystemseng.2012.08.005

Tullo, E., Fontana, I., Diana, A., Norton, T., Berckmans, D., \& Guarino, M. (2017). Application Note: Labelling, a Methodology to Develop Reliable Algorithm in PLF. Computers and Electronics in Agriculture, 142, 424-428. doi:10.1016/j.compag.2017.09.030

Volpi, D., Vigas, V. P., Alves, F. V., Silva, G. O., \& Saraiva, E. F. (2020). An Application of Hotelling's T2 Test for the Comparison of the Visual-acoustic Method in the Identification of Ingestive Cattle Behaviour. Brazilian Journal of Biometrics, 38(1), 79-91. 
Guilherme Defalque was born in Buritama, São Paulo, Brazil on May 7th, 1991. He obtained his Computer Engineering (UFMS), Master in Computer Engineering (UFMS) and is currently a doctoral student in computer science (UFMS). His main research interests are digital circuit designs, precision livestock, IOT and sensors design. Ricardo Ribeiro Santos is with the College of Computing of the Federal University of Mato Grosso do Sul. He got a PhD in computer science from the Institute of Computing of the State University of Campinas (UNICAMP), in 2007. He was a visiting scholar at the Department of Civil and Environmental Enginnering of the Stanford University in 2018.

Victor Leonardo Yoshimura was born in Campo Grande, Mato Grosso do Sul, Brazil on May 3rd, 1977. He obtained his Electrical Engineer, Master in Electrical Engineering and Doctor in Electrical Engineering degrees from UFMS (1999), UFSC (2002) and UNESP (2013), respectively. He also holds a degree in Mathematics from UFMT (2009). Currently, he is with Faculdade de Computação (UFMS) and his main research interests are LMI-based control designs and applications for electronic circuits.

Fabiana Villa Alves has a degree in Animal Science from Universidade Federal de Lavras (2002) and Ph.D. in Animal Science and Pastures from Escola Superior de Agricultura Luiz de Queiroz - ESALQ/USP (2007). Research focus is Sustainable Cattle Production with particular emphasis on animal welfare and thermal comfort under integrated systems. She is senior researcher at the Brazilian Agricultural Research Corporation - Embrapa Beef Cattle, in Campo Grande (MS), where she is also deputy supervisor for the Research Group on Production Systems (GSP). She collaborates on several national and international projects on her subject, being creator and leader of the recent and innovative public-private initiative "Carbon Neutral Brazilian Beef". Having an extensive network with scientists, policy makers and the industry all over Brazil and many parts of the world, she is member of several committees, being the official representative for Brazil on FAO's Global Agenda for Sustainable Livestock (GASL) and Livestock Environmental Assessment and Performance Partnership (LEAP). 